\title{
Development of 3D Printed Mitral Valve Constructs for Transcatheter Device Modeling of Tissue and Device Deformation
}

\author{
Marija Vukicevic, ${ }^{1}$ Shail Maharshi Mehta, ${ }^{2}$ K. Jane Grande-Allen, ${ }^{2}$ \\ and Stephen H. LitTle ${ }^{1}$ \\ ${ }^{1}$ The Methodist DeBakey Heart \& Vascular Center, 6550 Fannin Street, Suite 1851, Houston, TX 77030, USA; and ${ }^{2}$ Department \\ of Bioengineering, Rice University, 6566 Main St., Houston, TX 77030, USA
}

(Received 23 August 2021; accepted 6 February 2022; published online 26 February 2022)

Associate Editor Arash Kheradvar oversaw the review of this article.

\begin{abstract}
Transcatheter mitral valve repair (TMVR) therapies offer a minimally invasive alternative to surgical mitral valve (MV) repair for patients with prohibitive surgical risks. Pre-procedural planning and associated medical device modeling is primarily performed in silico, which does not account for the physical interactions between the implanted TMVR device and surrounding tissue and may result in poor outcomes. We developed 3D printed tissue mimics for modeling TMVR therapies. Structural properties of the mitral annuli, leaflets, and chordae were replicated from multi-material blends. Uniaxial tensile testing was performed on the resulting composites and their mechanical properties were compared to those of their target native components. Mimics of the MV annulus printed in homogeneous strips approximated the tangent moduli of the native mitral annulus at $2 \%$ and $6 \%$ strain. Mimics of the valve leaflets printed in layers of different stiffnesses approximated the force-strain and stress-strain behavior of native MV leaflets. Finally, mimics of the chordae printed as reinforced cylinders approximated the force-strain and stress-strain behavior of native chordae. We demonstrated that multi-material $3 \mathrm{D}$ printing is a viable approach to the development of tissue phantoms, and that printed patient-specific geometries can approximate the local deformation force which may act upon devices used for TMVR therapies.
\end{abstract}

Keywords-Mechanical testing, 3D printing, Mitral valve, 3D print materials, Transcatheter device modeling.

Address correspondence to Stephen H. Little, The Methodist DeBakey Heart \& Vascular Center, 6550 Fannin Street, Suite 1851, Houston, TX 77030, USA. Electronic mail: Shlittle@houstonmethodist.org

Marija Vukicevic and Shail Maharshi Mehta-First co-authors

\section{INTRODUCTION}

Mitral valve diseases are among the most prevalent heart diseases, and their prevalence increases with age. ${ }^{16}$ One of the most common defects of the mitral valve is mitral valve regurgitation (MR), affecting 7 million patients in the US annually. ${ }^{10}$ The traditional treatments for MR are surgical repair or replacement of the mitral valve (MV). However, as many as $49 \%$ of patients cannot undergo surgical treatment for severe degenerative MR due to advanced age, multiple comorbidities, and high surgical risks. ${ }^{23}$ There are several novel minimally-invasive therapies for mitral valve repair and replacement targeted to such patients. ${ }^{9}$ Pre-procedural planning of procedures such as transcatheter mitral valve repair (TMVR) is primarily based on digital anatomic models created from clinical imaging data. However, such digital-only modeling fails to incorporate the bidirectional deformation that occurs between the repair device and local mitral valve tissue as shown in Fig. 1. For example, when a nitinol TMVR (see Fig. 1a) device is deployed within a native mitral valve there are several deformation events that are expected: (i) the native mitral annulus is forced into a more circular configuration by the device; and the fully expanded device is compressed by the native annulus. This is an important aspect of device sizing since anchoring of the device often requires a $10-15 \%$ oversizing against the native annulus, thus creating consistent radial tension by the nitinol frame. (ii) The TMVR device necessarily displaces both anterior and posterior mitral leaflets into a vertical position within the LV (see Figs. $1 \mathrm{~b}$ and 1c). The displaced anterior leaflet can create significant 
LVOT obstruction, however the magnitude of anterior leaflet displacement is constrained by its attachment to the chordae tendineae. As such, the sub-valvular apparatus may constrain the TMVR device deployment within the LVOT region or influence the final alignment of the entire device frame. Thus, there is need to develop patient-specific physical models to better inform patient and device selection protocols. The consideration of these deformation outcomes could influence the clinical decisions about type of TMVR device (e.g. self-expanding nitinol frame vs balloon-expandable cobalt-chromium frame); the size of the device for a specific patient; or even the decision to proceed with high risk surgery to avoid a predicted poor outcome with TMVR.

3D printing methods that replicate tissue-like mechanical properties could reveal important anatomic configurations that better predict patient outcomes from TMVR therapy, and may become an important tool for patient and device selection. Initially, 3D printed medical phantoms were fabricated predominantly of hard materials and used solely to demonstrate complex tissue geometry. The development of multi-material printers and flexible materials allowed for the development of flexible 3D printed phantoms for functional evaluation and medical device testing. ${ }^{14}$ Given the sensitivity of interactions, between mitral tissue and medical devices, i.e., 3D printed replicas should be fabricated using materials exhibiting mechanical properties similar to those of biological tissue. For example, since even minimal obstruction of the LVOT can have lethal consequences, 3D printed mitral leaflet constructs should replicate not only the geometry of the leaflet, but also the mechanical properties to allow replication of tissue deformation events during a TMVR procedure. However, data on the mechanical properties of $3 \mathrm{D}$ printed materials used for fabrication of cardiovascular models is limited.

The mitral valve apparatus is a complex and dynamic structure composed of the mitral annulus, anterior and posterior leaflets, chordae tendineae, and papillary muscles. The microstructure of the mitral valve elements, especially the leaflets and chordae, is responsible for effective function of the entire mitral apparatus. The mitral annulus is a collagenous structure, with the continuous anterior portion demonstrating much stiffer mechanical behavior than the non-continuous posterior annulus segments. ${ }^{7,}{ }^{1}$ The inner structure of the mitral leaflets is organized in three different layers: the fibrosa facing the left ventricle, the spongiosa as the middle layer, and the atrialis on the atrial side. The layers each have different mechanical properties as they possess different amounts of elastin and load-bearing collagen fibers. ${ }^{11}$ In contrast, the chordae tendineae are comprised of an inner collagen core, a surrounding layer of elastic fibers, and an outer layer of endothelial cells. ${ }^{15}$

Few studies have investigated the mechanical performance of 3D printed materials used for the replication of cardiovascular tissue. With the recent development of new elastic photopolymers (such as Agilus and Rigur, Stratasys, Eden Prairie, Minnesota), there is a need for more specific testing and characterization of the mechanical properties of these photopolymers to determine their ability to replicate the mechanics of the mitral valve apparatus.

In this study, we developed novel 3D printed composites that approximated the mechanical properties of components of the mitral valve apparatus, including the mitral annulus, leaflets, and chordae. These composites were developed by replicating representative design elements of the native architecture of these components. Mechanical properties of these composites were investigated using uniaxial tensile testing and compared to those of the target biological tissue at physiologically relevant strains. Mechanical characterization of the $3 \mathrm{D}$ printed constructs involved measurements of ultimate stress and strain, elastic moduli, stress-strain relationships, and force-strain relationships.

\section{MATERIALS AND METHODS}

\section{Leaflet Design and Fabrication}

To test and select the optimal combination of materials for each mitral valve element, we created different sample structures representative of the ultrastructure of the mitral annulus, leaflets, and chordae. All material samples were created using CAD-based software platforms 3-Matic (Materialize, Belgium) and Solidworks (Dassault Systems, Waltham, MA). Samples were fabricated using a PolyJet 3D printer (Object 500 Connex3, Stratasys, Eden Prairie, MN). Agilus and Rigur of different shore hardness were selected as the print materials. Printed materials with higher shore hardness values are generally associated with higher stiffness. Of the range of materials used in this study, the softest material was shore 27 , while the stiffest material was shore 95 .

\section{Mitral Annulus}

Mitral annulus samples were designed as test coupons, or strips, that were $1 \mathrm{~mm}$ thick, $5 \mathrm{~mm}$ wide, and $20 \mathrm{~mm}$ long, and 3D printed using Agilus and Rigur material in a homogeneous configuration with a range of stiffnesses. The Annulus A1, Annulus A2, and Annulus A3 samples were 3D printed of Agilus shore 
70 , shore 85 , and shore 95 , respectively, whereas the Annulus B1, Annulus B2, and Annulus B3 samples were $3 \mathrm{D}$ printed from Rigur shore 70 , shore 85 , and shore 95 , respectively.

\section{Mitral Leaflets}

Due to the complexity and multi-layered ultrastructure of the mitral valve leaflets, we created both homogeneous and multi-material printed samples of mitral leaflets. The homogeneous 'Leaflet A' samples were fabricated of Agilus shore $27(20 \mathrm{~mm} \times 5$ $\mathrm{mm} \times 1 \mathrm{~mm})$. The 'Leaflet B' samples were comprised of two $1 \mathrm{~mm}$ thick layers $(20 \mathrm{~mm} \times 5 \mathrm{~mm} \times 2 \mathrm{~mm})$, in which one layer was fabricated with Agilus shore 27 and the second layer with Agilus shore 50. The 'Leaflet C' samples were made of a $1 \mathrm{~mm}$ thick inner layer printed with Agilus shore 27, and a $0.4 \mathrm{~mm}$ thick outer shell printed of Agilus shore 70. Patient-specific mitral valve leaflets were reconstructed from computed tomography (CT) images of patient mitral valves using the imaging processing platform Mimics (Materialize, Belgium). The CT images were acquired using Siemens Force System with optimal contrast protocol. Image resolution was $512 \times 512$ pixels, with slice thickness of $0.6 \mathrm{~mm}$.

These leaflets, designated as sample group 'Leaflet D', were comprised of an inner layer printed using Agilus shore 27 and an outer shell printed using Agilus shore 70 and had a combined leaflet thickness that varied between 1 and $3 \mathrm{~mm}$ (as shown in Fig. 2). The patient-specific geometry of the leaflets and their irregular thickness was preserved.

\section{Mitral Chordae}

To investigate the most appropriate printed material combination for the fabrication of chordae with native geometries reconstructed from patient CT scans, ide- alized chordal samples in the form of cylinders with fiber reinforcements were designed. A series of different fiber types were tested, including spiral, sinusoidal wave, and rope-like fibers. Reinforcement fibers and base materials were both printed to be $20 \mathrm{~mm}$ long. The spiral fiber reinforcement was $0.5 \mathrm{~mm}$ in diameter, whereas the number of revolutions per sample length was varied to influence their pitch length. After a series of iterative assessments that varied the reinforcement thickness and number of revolutions (illustrated in Appendix), we selected spiral reinforcements with 30 revolutions per $20 \mathrm{~mm}$ sample length for further study. The sinusoidal reinforcement fibers were designed using an equation-driven curve defined with the expression $\mathrm{A} \sin (\omega t)$, where $\omega$ represented angular frequency, A represented amplitude, and t represented the period. After another series of iterative assessments (data not shown), composite structures containing sinusoidal reinforcements with $\omega=1, \mathrm{~A}=0.5$, and $t=0.4$ were chosen for further study. To build on the fiber complexity, rope-like reinforcements were designed as three intertwined fibers of $1 \mathrm{~mm}$ thickness and $4 \mathrm{~mm}$ pitch. All fiber reinforcements were designed in Solidworks and incorporated into cylindrical chordal models using the CAD-based 3-Matic (Materialize, Belgium) platform. We also designed and tested samples of chordae without fiber reinforcements for reference.

The 'Chordae A1' and 'Chordae A2' sample groups were homogeneous cylindrical samples printed of Agilus shore 30 and shore 70 , respectively. The 'Chordae B1' samples had spiral reinforcements, the 'Chordae B2' samples had sinusoidal reinforcements, and the 'Chordae B3' samples had rope-like reinforcements. The cylindrical base for all these three groups was printed of Agilus shore 70 and the reinforcement fibers were printed of Agilus shore 95. The printed annulus, leaflet, and chordae designs are summarized in Fig. 2.
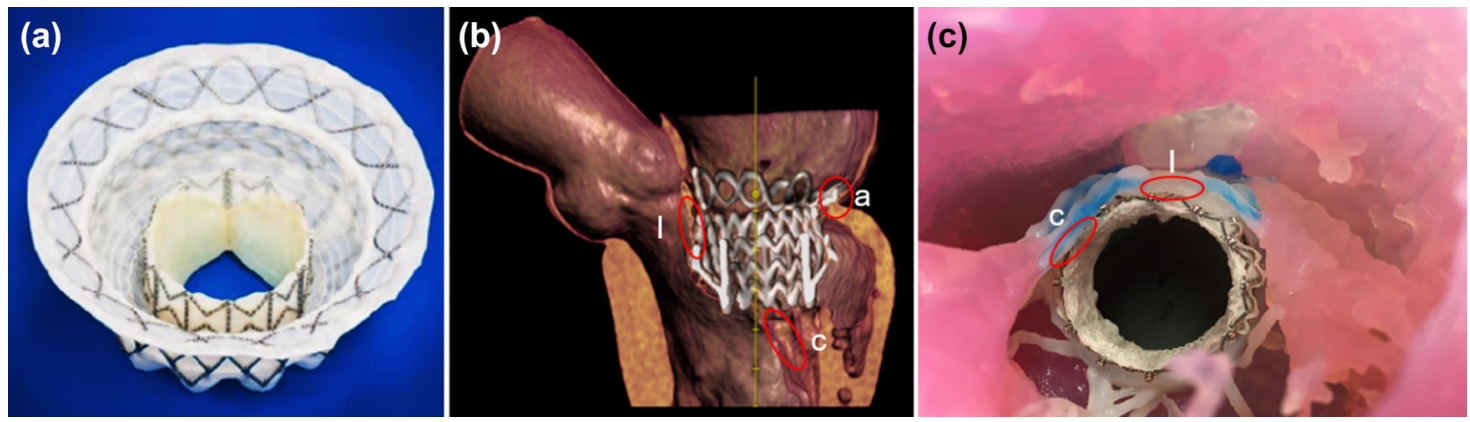

FIGURE 1. Bidirectional deformation of cardiac tissue and device. (a) Nitinol transcatheter mitral valve replacement (TMVR) device (Intrepid, Medtronic, USA); (b) Computed tomography image of the TMVR device implanted into a 3D printed mitral valve model incorporating tissue-specific material properties. (c) View from the left ventricle of the TMVR device deployed within a 3D printed mitral valve model. Regions of device and tissue deformation of the annulus (a), leaflet (I), and chordae tendineae (c) are identified (red ovals). 


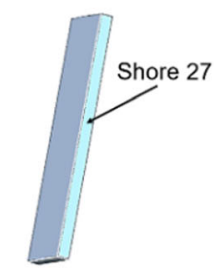

Leaflets A

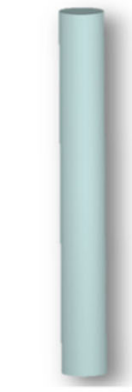

Chordae A1 (Shore 30)

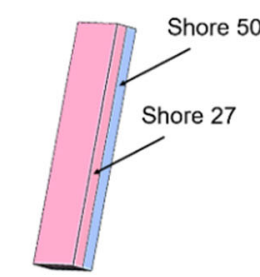

Leaflets B

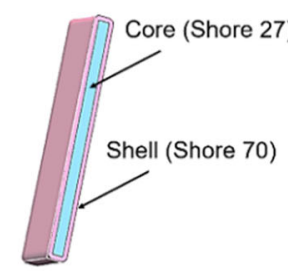

Leaflet C

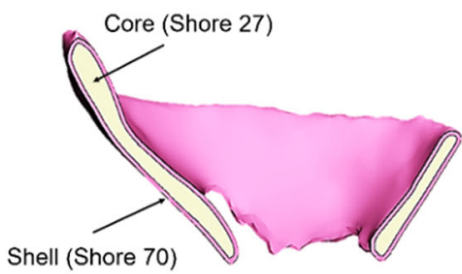

Leaflet D

FIGURE 2. Design outline for 3D printed mitral valve constructs.

\section{Selection of Relevant Physiological Strains}

Different studies have found that the strain values of mitral tissue vary among mitral valve elements, and different ranges of physiological and maximal strain values have been reported. Based on a review of this literature, we analyzed the mechanical behavior of our printed constructs within physiologically relevant strains for each mitral valve element (Figure 3). Thus, we investigated the $3 \mathrm{D}$ printed annulus samples up to strain of $10 \%,{ }^{7}$ and the $3 \mathrm{D}$ printed leaflet samples up to $25 \%$ strain. The strains experienced by chordae tendineae depend on their size and location. However, we were primarily interested in studying material behavior within physiologically averaged deformations. Therefore, we examined the mechanical behavior of chordae samples up to $10 \%$ strain. $^{12}$

\section{Tensile Testing Procedure}

Tensile testing was performed on printed model samples of the mitral valve annulus, leaflets, and chordae using a Bose Electroforce ELF 3200 Series III mechanical testing device as described previously. ${ }^{22}$ Samples were elongated either to failure or to the maximum instrument extension at a rate of $0.1 \mathrm{~mm} / \mathrm{s}$ to apply a consistent strain rate across all printed samples. A subset of our samples was also tested at a 10x higher strain rate to quantify Agilus' rate-dependent mechanical behavior.
In order to compare printed material behavior with that of biological tissue, tensile testing was also performed on chordae samples extracted from human tissue, as described previously. ${ }^{5}$ All human tissue samples used within this study were collected under an institutional review board approved protocol (IRB (3N) 0511-0100). The samples were obtained from recipient hearts of male patients (59-68 years old) that underwent heart transplantation. The tissue samples were obtained immediately after the transplantation and pathological inspection.

Chordae were preconditioned to $10 \%$ strain at $1 \mathrm{~Hz}$ for 20 cycles, and then were subjected to a pull-tofailure protocol at $0.1 \mathrm{~mm} / \mathrm{s}$. Testing was carried out in phosphate buffered saline solution (PBS) at $37^{\circ} \mathrm{C}$. Data from existing literature was used to make comparisons with printed material for mitral valve leaflets and annuli. Three replicates for each group were tested.

\section{Quantification of Mechanical Properties}

Force-displacement data was converted to stressstrain data by dividing the force by the cross-sectional area perpendicular to the direction of testing to calculate stress, and by dividing the sample displacement by the sample gauge length to calculate engineering strain. Measurements of initial sample thickness and width (for cross-sectional area calculations) were obtained with ImageJ (NIH, Bethesda, MD) using 


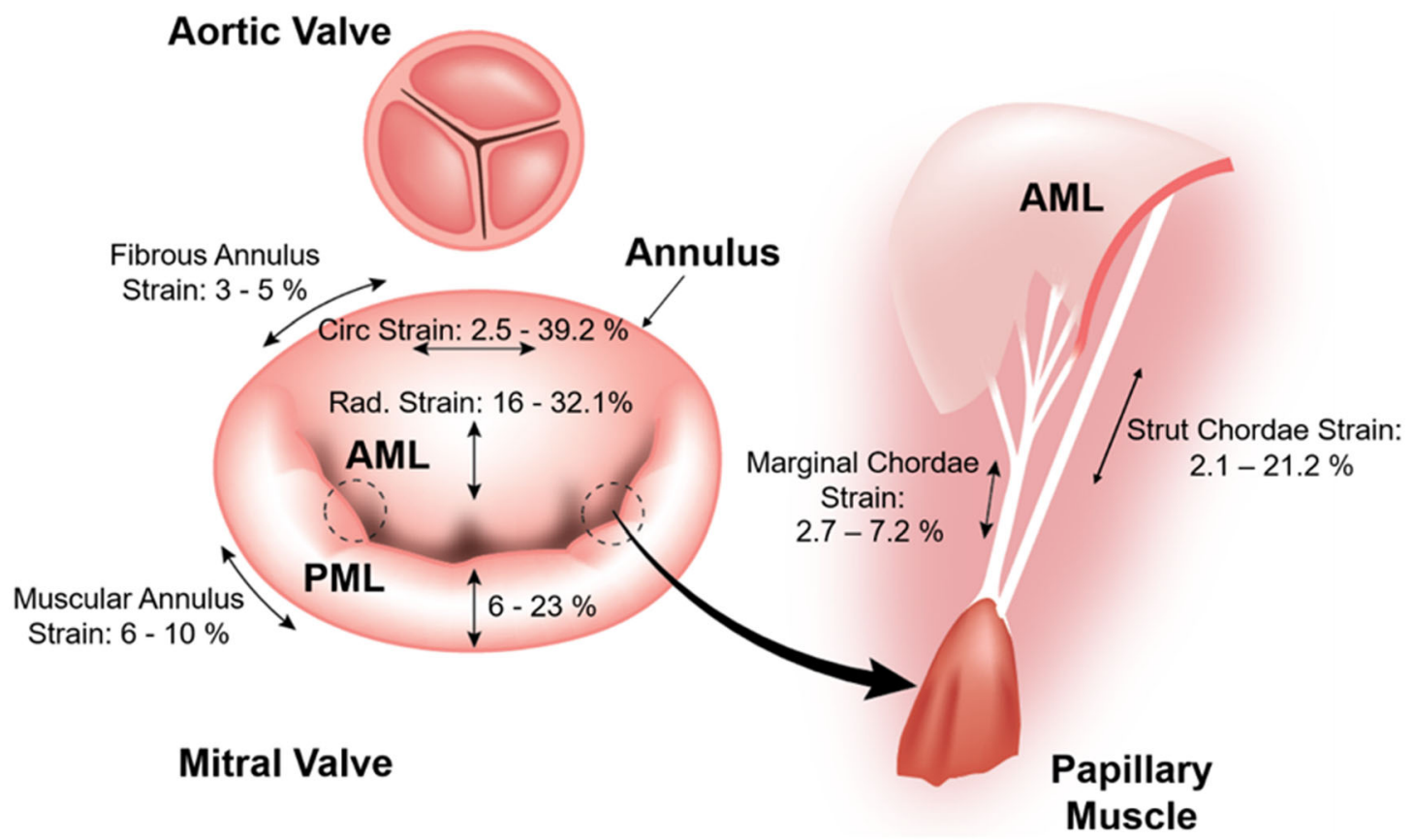

FIGURE 3. Range of reported physiological strains for the mitral valve apparatus were extracted from Gunning et al., Sacks et al., He et al., El-Tallawi et al., Grande-Allen et al., Liao et al. ${ }^{7}$.

images of samples taken via a stereomicroscope (Leica Microsystems, Buffalo Grove, MN).

Stress-strain and force-strain curves were generated up to the aforementioned strain levels for all printed components of the mitral valve apparatus. These curves were further analyzed to determine the mechanical behavior at specific strain magnitudes. For printed mitral valve annuli, we measured average force and average stress at 2 and $6 \%$ strain, in addition to tangent modulus at 2 and $6 \%$ strain. These values were selected to allow us to make comparisons with testing data for biological tissue in existing literature, as well as for their physiological relevance. The tangent modulus at a specific strain level was measured by first fitting a quadratic curve locally around the datapoint corresponding to that strain level, then finding the equation of the line tangent to that quadratic curve at that strain level. The slope of this tangent line was taken to be the tangent modulus at that strain level. For printed mitral valve leaflets, ultimate force, stress and strain were obtained, in addition to measurements of elastic modulus between 5 and $25 \%$ strain. Similar characterization was performed on mitral leaflet data with comparison to published literature. ${ }^{22}$ Such measurements were also obtained for printed and native chordae, where the elastic modulus was measured between 0 and $10 \%$ strain.

\section{Statistical Analysis}

The average stress-strain curves for each individual group were generated by obtaining the stress value at strain values closest to a desired strain increment for a replicate in that group, then averaging stress values across all replicates for that group. This process was then repeated across all strain increments and groups to obtain averaged stress-strain curves. All data processing was performed using custom Python code, ${ }^{17}$ with the resulting values reported as mean $\pm \mathrm{SD}$. Oneway ANOVAs were performed on tensile elastic modulus data from printed constructs and biological tissue. Post-hoc testing was performed using Tukey's HSD test, and statistical significance was accepted for $p$ values less than 0.05 .

\section{RESULTS}

\section{Mechanical Testing of 3D Printed Mitral Annulus}

After analyzing the force-strain and stress-strain behavior of Agilus and Rigur annulus sample, it was determined that the Annulus A3 and Annulus B3 samples demonstrated the highest forces under strain. The Agilus material samples (Annulus A1-A3) exhibited higher forces at all strain values as compared to the Rigur material samples (Annulus B1-B3, Fig 4a). These trends were preserved for the stress-strain curves as well (Fig. 4b). All 3D printed materials exhibited 
(a)

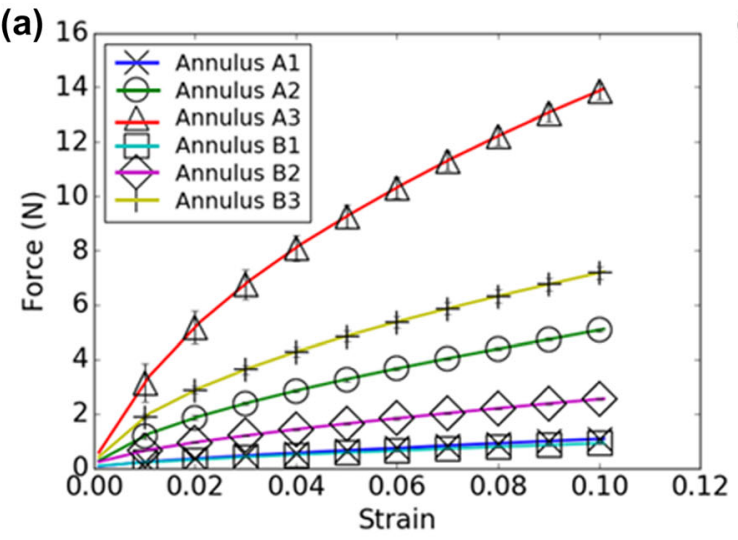

(b)

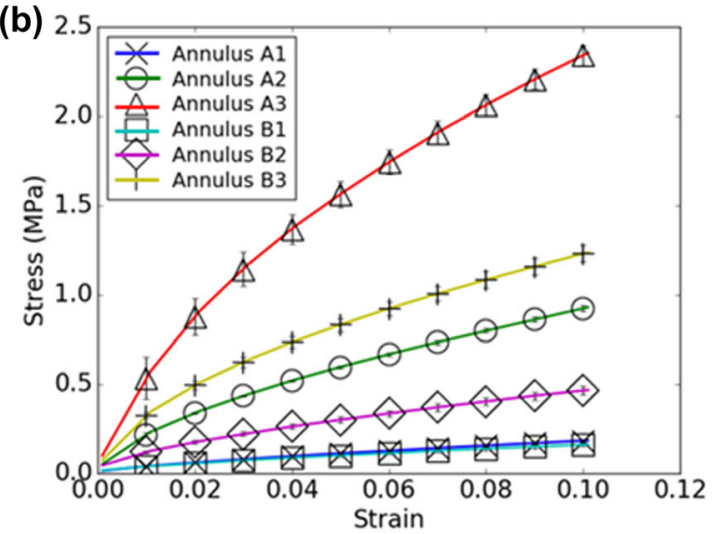

(c)

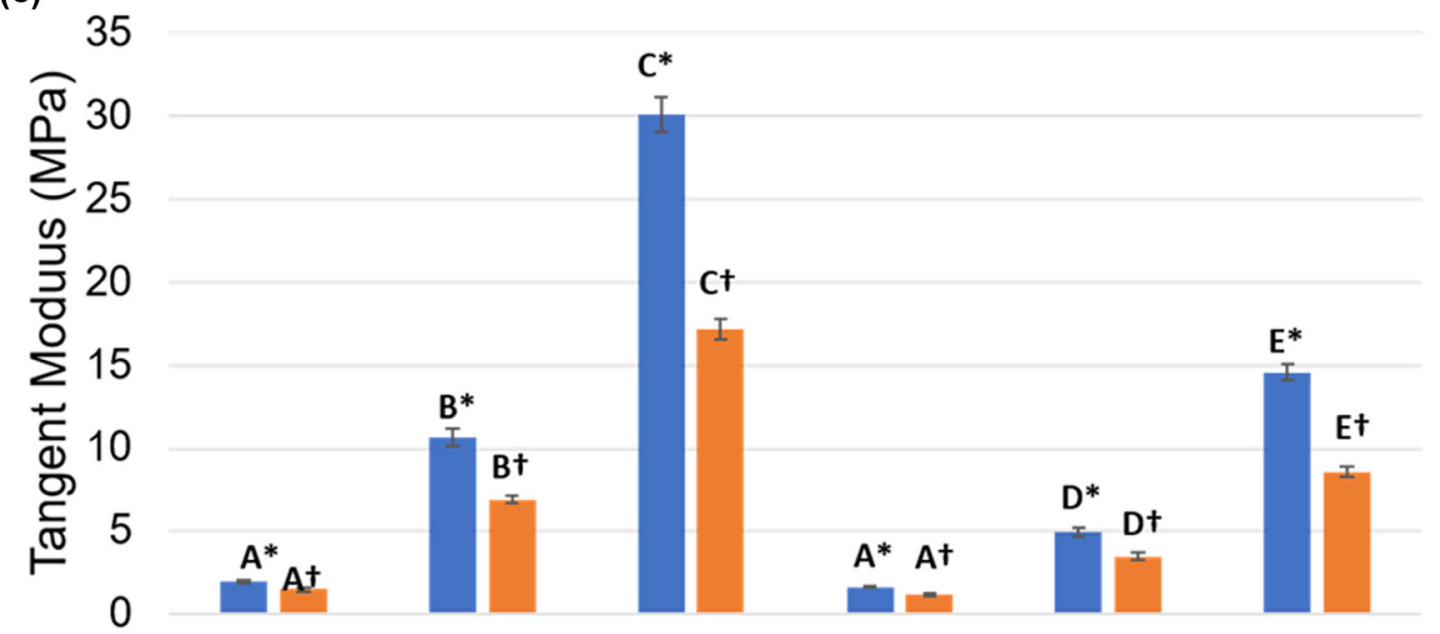

Annulus A1 Annulus A2 Annulus A3 Annulus B1 Annulus B2 Annulus B3 - $2 \%=6 \%$

FIGURE 4. a Force-strain and b stress-strain curves for 3D printed mitral valve annulus samples for physiological strains. c Tangent Elastic moduli for 3D printed mitral valve annulus samples. Results are presented as mean \pm SD. $N=3$ for all indicated groups. The tangent moduli at different strains were not compared statistically. Comparisons between tangent moduli at $2 \%$ strain are indicated using *, and comparisons between tangent moduli at $6 \%$ strain are indicated using $\dagger$. Groups sharing a letter are not significantly different from each other. ${ }^{*} p<0.05$ and $\dagger p<0.05$ for all indicated groups.

non-linear mechanical behavior, with initial highstiffness behavior in the small strain regime $(0-2 \%)$, followed by a region of lower stiffness at higher strains $(2-10 \%)$. The force and stress values at 2 and $6 \%$ strain are presented in Table 1.

The tangent moduli of 3D printed samples of Agilus and Rigur at $2 \%$ and $6 \%$ strain were also determined (Fig. $4 \mathrm{c}$ and Table 1). Tangent moduli measured at $2 \%$ strain were higher than tangent moduli measured at $6 \%$ for all sample groups. Annulus material printed using a higher shore hardness demonstrated higher tangent moduli; however, material printed using Rigur material demonstrated lower tangent moduli than material printed using Agilus. All comparisons between Agilus and Rigur constructs for tangent moduli measured at the same strain levels were sig- nificantly different for all sample groups except for the comparison of Annulus A1 and B1. The overall performance of Agilus material was more similar to native annular tissue, therefore the following tests were performed on Agilus materials (Tables 2 and 3).

\section{Mechanical Testing of 3D Printed Mitral Valve Leaflets}

Force-strain curves for both printed and biological mitral valve tissue were determined and depicted in Fig. 5a. For initial deformations (strains $<12 \%$ ), elongation of the homogeneous Leaflet A samples resulted in forces that were similar to those of porcine anterior and posterior leaflets. At higher strain levels, the composite materials (Leaflet B, C, and D samples) 
TABLE 1. Mechanical property measurements for printed mitral valve annulus constructs.

\begin{tabular}{|c|c|c|c|c|c|c|c|}
\hline \multirow[b]{2}{*}{$\begin{array}{l}\text { Material } \\
\text { property }\end{array}$} & \multirow[b]{2}{*}{$\begin{array}{c}\text { Shore } \\
\text { hardness }\end{array}$} & \multicolumn{3}{|c|}{ At strain $2 \%$} & \multicolumn{3}{|c|}{ At strain $6 \%$} \\
\hline & & $\begin{array}{l}\text { Tangent modulus } \\
(2 \%)(\mathrm{MPa})\end{array}$ & $\begin{array}{l}\text { Stress } \\
(\mathrm{MPa})\end{array}$ & Force $(\mathrm{N})$ & $\begin{array}{c}\text { Tangent modulus } \\
(6 \%)(\mathrm{MPa})\end{array}$ & $\begin{array}{l}\text { Stress } \\
(\mathrm{MPa})\end{array}$ & Force $(\mathrm{N})$ \\
\hline Annulus A1 & 70 & $1.94 \pm 0.09^{\mathrm{a}}$ & $0.06 \pm 0.00^{\mathrm{a}}$ & $0.35 \pm 0.02^{\mathrm{a}}$ & $1.49 \pm 0.11^{\mathrm{a}}$ & $0.13 \pm 0.00^{\mathrm{a}}$ & $0.74 \pm 0.02^{\mathrm{a}}$ \\
\hline Annulus A2 & 85 & $10.66 \pm 0.56^{b}$ & $0.34 \pm 0.01^{\mathrm{b}}$ & $1.85 \pm 0.08^{b}$ & $6.92 \pm 0.19^{b}$ & $0.66 \pm 0.01^{b}$ & $3.66 \pm 0.05^{b}$ \\
\hline Annulus A3 & 95 & $30.10 \pm 1.02^{c}$ & $0.87 \pm 0.10^{c}$ & $5.19 \pm 0.60^{c}$ & $17.20 \pm 0.62^{c}$ & $1.74 \pm 0.07^{c}$ & $10.33 \pm 0.39^{c}$ \\
\hline Annulus B1 & 70 & $1.65 \pm 0.03^{\mathrm{a}}$ & $0.05 \pm 0.00^{a}$ & $0.32 \pm 0.01^{a}$ & $1.18 \pm 0.09^{a}$ & $0.11 \pm 0.01^{a}$ & $0.64 \pm 0.02^{\mathrm{a}}$ \\
\hline Annulus B2 & 85 & $4.96 \pm 0.24^{d}$ & $0.17 \pm 0.01^{a}$ & $0.95 \pm 0.01^{\mathrm{a}}$ & $3.46 \pm 0.22^{d}$ & $0.33 \pm 0.02^{d}$ & $1.83 \pm 0.04^{d}$ \\
\hline Annulus B3 & 95 & $14.57 \pm 0.52^{\mathrm{e}}$ & $0.49 \pm 0.02^{d}$ & $2.87 \pm 0.13^{d}$ & $8.58 \pm 0.31^{e}$ & $0.92 \pm 0.04^{e}$ & $5.37 \pm 0.21^{e}$ \\
\hline
\end{tabular}

Annulus A1, A2, and A3 were printed of Agilus material of shore 70, 85, and 95 hardness, respectively. Annulus B1, B2, and B3 were printed of Rigur material of shore 70,85 , and 95 hardness, respectively. Groups sharing a letter within the same column are not significantly different from each other ( $p<0.05$ for all indicated groups). Results are presented as mean \pm SD. $N=3$.

TABLE 2. Mechanical property measurements for printed and biological mitral valve leaflet constructs.

\begin{tabular}{|c|c|c|c|c|c|c|}
\hline $\begin{array}{l}\text { Material prop- } \\
\text { erty }\end{array}$ & $\begin{array}{c}\text { Shore } \\
\text { hardness }\end{array}$ & $\begin{array}{l}\text { Elastic modulus } \\
(\mathrm{MPa})\end{array}$ & $\begin{array}{l}\text { Maximum observed } \\
\operatorname{strain}(\%)\end{array}$ & $\begin{array}{l}\text { Maximum observed } \\
\text { force }(N)\end{array}$ & $\begin{array}{l}\text { Maximum observed } \\
\text { stress }(\mathrm{MPa})\end{array}$ & $\begin{array}{l}\text { Failure } \\
\text { achieved }\end{array}$ \\
\hline Leaflets A & 27 & $0.51 \pm 0.01$ & $58 \pm 3$ & $1.38 \pm 0.12$ & $0.30 \pm 0.01$ & $\mathrm{~N}$ \\
\hline Leaflets B & $27 / 40$ & $0.63 \pm 0.01$ & $64 \pm 3$ & $4.25 \pm 0.41$ & $0.41 \pm 0.01$ & $\mathrm{~N}$ \\
\hline Leaflets C & $27 / 70$ & $0.51 \pm 0.05$ & $58 \pm 1$ & $3.11 \pm 0.33$ & $0.31 \pm 0.04$ & $\mathrm{~N}$ \\
\hline Leaflets D & $27 / 70$ & $0.95 \pm 0.02$ & $60 \pm 8$ & $7.07 \pm 1.30$ & $0.54 \pm 0.11$ & $\mathrm{Y}$ \\
\hline $\begin{array}{l}\text { Mitral Anterior } \\
\text { Leaflet }\end{array}$ & $\mathrm{N} / \mathrm{A}$ & $2.20 \pm 0.55$ & $49 \pm 4$ & $5.90 \pm 1.60$ & $0.96 \pm 0.12$ & $\mathrm{Y}$ \\
\hline $\begin{array}{l}\text { Mitral Posterior } \\
\text { Leaflet }\end{array}$ & $\mathrm{N} / \mathrm{A}$ & $1.74 \pm 0.48$ & $56 \pm 6$ & $3.74 \pm 1.34$ & $0.61 \pm 0.16$ & $\mathrm{Y}$ \\
\hline
\end{tabular}

All printed leaflets were fabricated using Agilus. Leaflets A were printed with a homogeneous shore 27 formulation, Leaflets B were printed as bilayer constructs of shore 27 and shore 50 hardness, Leaflets $C$ were printed with a shore 27 inner core and shore 70 outer shell, and Leaflets D were printed to patient-specific geometries with a shore 27 inner core and shore 70 outer shell. Results are presented as mean \pm SD. $N=3$.

TABLE 3. Mechanical property measurements for printed and biological mitral valve chordae constructs.

\begin{tabular}{|c|c|c|c|c|c|c|}
\hline Material property & $\begin{array}{c}\text { Shore } \\
\text { hardness }\end{array}$ & $\begin{array}{l}\text { Elastic modulus } \\
(\mathrm{MPa})\end{array}$ & $\begin{array}{l}\text { Maximum observed } \\
\text { strain (\%) }\end{array}$ & $\begin{array}{l}\text { Maximum observed } \\
\text { force }(\mathrm{N})\end{array}$ & $\begin{array}{l}\text { Maximum observed } \\
\text { stress }(\mathrm{MPa})\end{array}$ & $\begin{array}{l}\text { Failure } \\
\text { achieved }\end{array}$ \\
\hline Chordae A1 & 30 & $0.52 \pm 0.02$ & $53 \pm 5$ & $1.13 \pm 0.08$ & $0.24 \pm 0.02$ & $\mathrm{~N}$ \\
\hline Chordae A2 & 70 & $1.43 \pm 0.09$ & $49 \pm 6$ & $3.17 \pm 0.29$ & $0.66 \pm 0.06$ & $\mathrm{~N}$ \\
\hline Chordae B1 & $70 / 95$ & $3.50 \pm 0.38$ & $47 \pm 7$ & $6.18 \pm 0.66$ & $1.22 \pm 0.18$ & $\mathrm{Y}$ \\
\hline Chordae B2 & $70 / 95$ & $2.80 \pm 0.65$ & $60 \pm 17$ & $6.45 \pm 1.96$ & $1.28 \pm 0.48$ & $\mathrm{Y}$ \\
\hline Chordae B3 & $70 / 95$ & $7.23 \pm 0.87$ & $56 \pm 2$ & $12.86 \pm 1.11$ & $2.54 \pm 0.20$ & $\mathrm{Y}$ \\
\hline $\begin{array}{l}\text { Mitral anterior } \\
\text { chordae }\end{array}$ & $\mathrm{N} / \mathrm{A}$ & $31.88 \pm 49.49$ & $16 \pm 7$ & $1.73 \pm 1.44$ & $4.32 \pm 4.55$ & $\mathrm{Y}$ \\
\hline $\begin{array}{l}\text { Mitral posterior } \\
\text { chordae }\end{array}$ & $\mathrm{N} / \mathrm{A}$ & $62.64 \pm 43.04$ & $13 \pm 2$ & $1.50 \pm 0.52$ & $6.45 \pm 4.24$ & $\mathrm{Y}$ \\
\hline
\end{tabular}

All printed chordae were fabricated using Agilus. Chordae A1 and A2 were printed using homogeneous formulations of shore 30 and shore 70 hardness, respectively. Chordae B1 were fabricated with spiral reinforcements, Chordae B2 were fabricated with sinusoidal reinforcements, and Chordae B3 were fabricated with rope-like reinforcements. Reinforcements were fabricated with shore 95 hardness, and base material was fabricated with shore 70 hardness. Results are presented as mean \pm SD. $N=3$.

exhibited force levels that were more similar to the biological leaflets (Fig. 5a).

Corresponding stress-strain curves for printed and biological mitral valve tissue were determined and plotted in Fig. 5b. The stress-strain behavior of prin- ted materials was approximately similar to that of biological valves; however, in a manner similar to what was observed with the force-strain curves, the opposite concavity of the printed material curves resulted in slightly overshooting the stress-strain response at low 
(a)

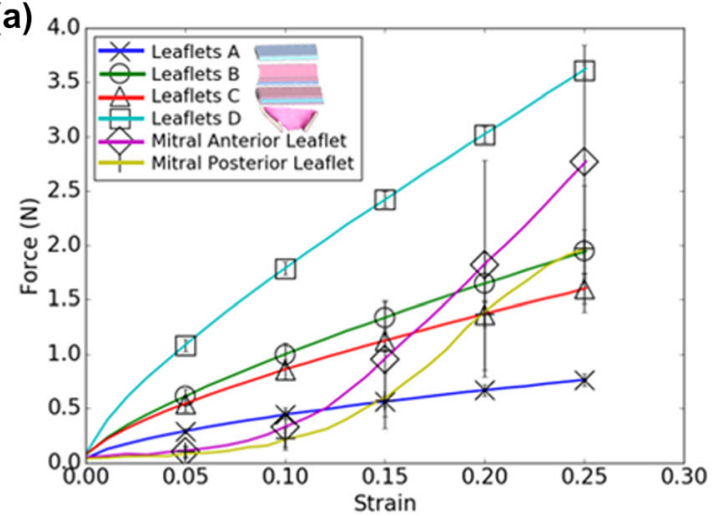

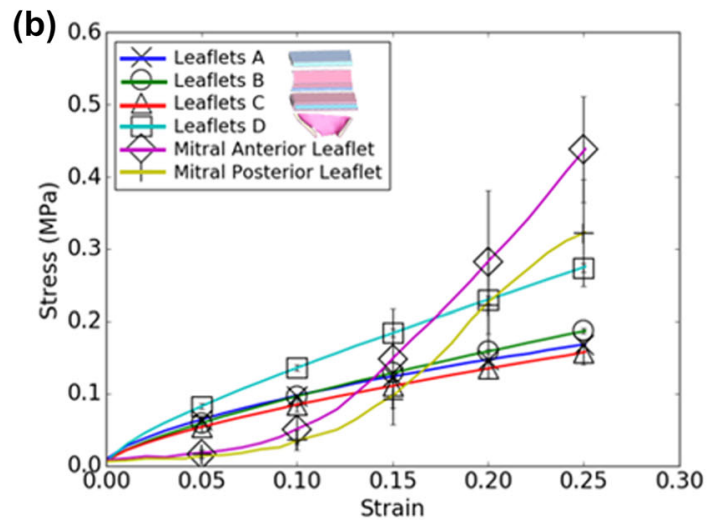

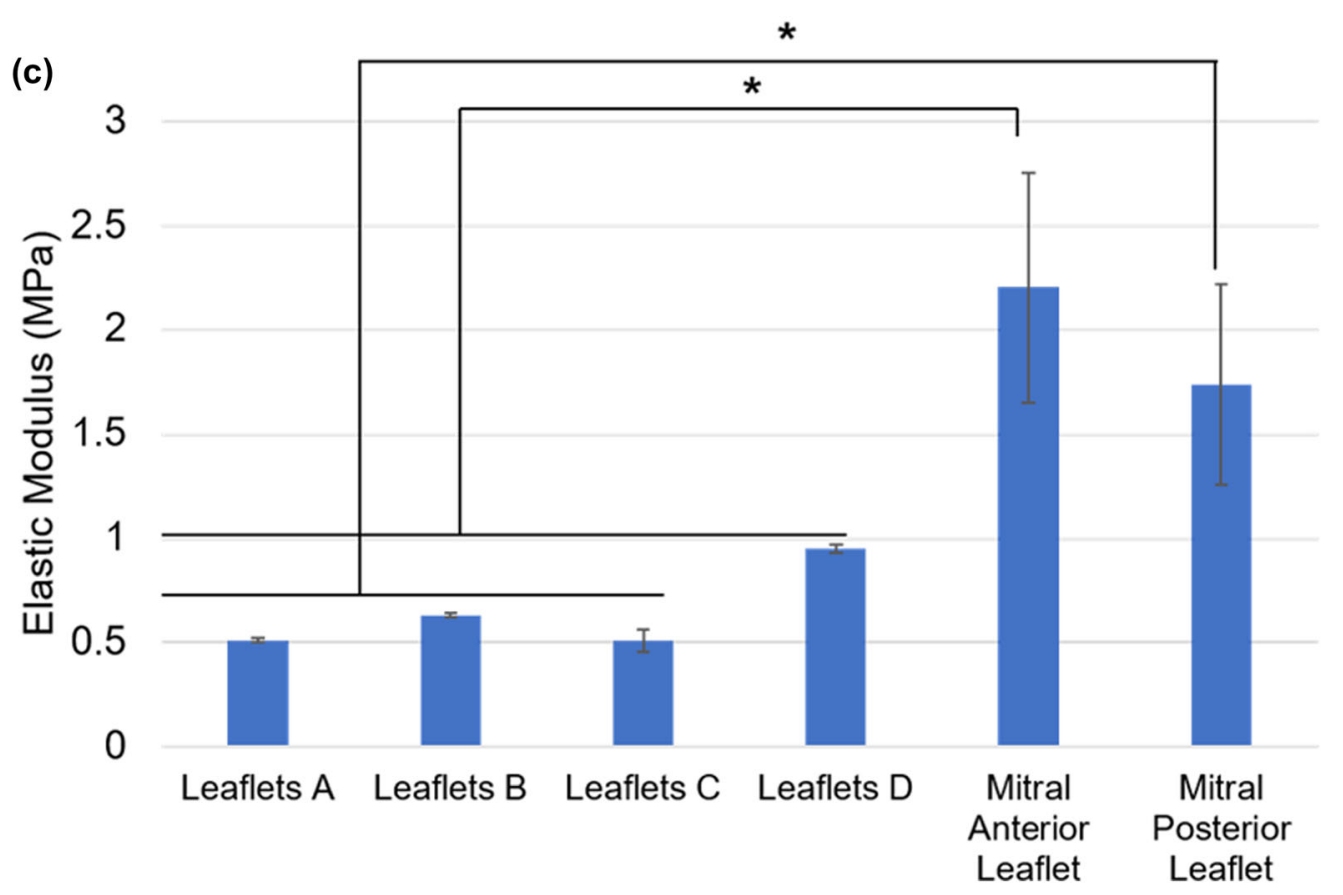

FIGURE 5. a Force-strain and b stress-strain curves for 3D printed mitral valve leaflet samples for physiological strains. $c$ Elastic moduli for 3D printed mitral valve leaflet samples. Moduli were measured between 5 and $25 \%$ strain. Results are presented as mean \pm SD. $N=3$ and ${ }^{*} p<0.05$ for all indicated groups. Model designs for composite printed structures are indicated on the figure legend.

strains and slightly undershooting the stress-strain response at high strains in comparison with biological leaflets. Leaflet A, B, and C samples showed a similar stress-strain response and matched biological stresses better at lower strains $(<15 \%)$, whereas Leaflet D samples indicated a better match at higher strains (Fig. 5b). When considering all sample groups, the printed materials were able to recapitulate the stresses displayed by biological samples between 12 and $20 \%$ strain.

The elastic modulus for each sample group was determined and plotted in Fig. 5C. Elastic modulus values, maximum observed stresses and forces, and maximum observed strain of all printed leaflet samples along with porcine anterior and posterior leaflet samples were presented in Table 2. There was no significant difference in elastic modulus among the printed materials. Elastic moduli for Leaflet A, B, and C samples were significantly lower than those of biological valves. However, the elastic moduli of Leaflet D and Mitral Posterior Leaflet samples were not statistically different from one another.

Ultimate strain measurements for all printed valves exceeded those of biological leaflets. The Leaflet A, B, and $\mathrm{C}$ samples did not undergo failure before the maximum extension limit of the tensile testing instrument was reached, indicating that the ultimate strains of these printed groups are even higher than indicated 
in Table 2. While the printed materials were unable to match the ultimate stress values of biological tissue, they were able to recapitulate the ultimate force values demonstrated by both anterior and posterior mitral valve tissue.

\section{Mechanical Testing of Biological and 3D Printed Mitral Valve Chordae}

The force-strain and stress-strain behavior of printed and biological chordae samples was determined and plotted in Fig. 6, showing comparisons between all printed samples (Figs. 6a and 6b), and between printed and biological samples (Figs. 6c and 6d). The homogeneous chordae sample groups Chordae A1 (shore 30) and A2 (shore 70) showed a lower force and stress response compared to the groups Chordae B1, B2, and B3, which were comprised of a base material (shore 70) and stiffer reinforcement (shore 95). Relative trends between all printed chordae groups were preserved across both force-strain and stress-strain curves.

Force-strain curve comparisons between the composite printed models and biological chordae indicated that printed composite chordae showed comparatively higher force responses than biological chordae at all
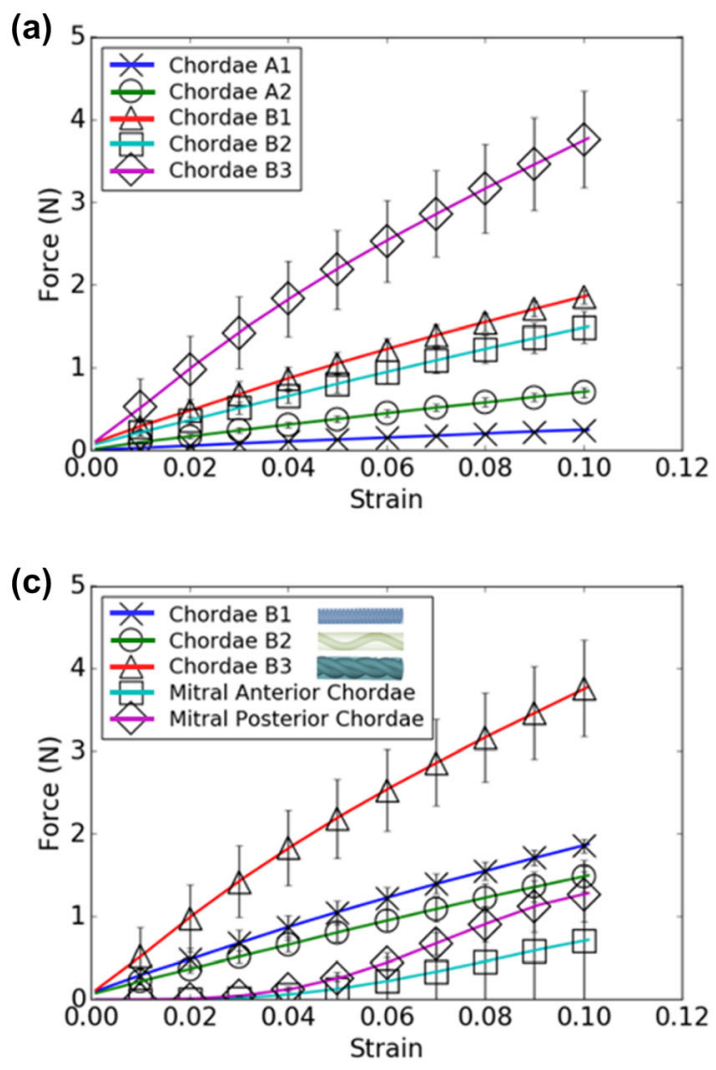

strain levels. Chordae models B1 and B2 showed the closest similarity in forces to biological chordae, but only at higher strain levels $(8-10 \%)$. Conversely, stress-strain curve comparisons between the printed composite and biological chordae indicated that the printed chordae could approximately match the stresses shown by biological chordae at low strain levels (0$5 \%$ ) but were unable to match their stress response at higher strains.

Elastic moduli for printed and biological chordae as measured between 0 and $10 \%$ of their stress-strain curves are shown in Fig. 7. Between the printed material models, the sample group Chordae B3 showed the highest elastic modulus, and composite models reinforced with Shore 95 fibers generally indicated a higher elastic modulus than the homogeneous models A1 and A2. Statistically significant differences between printed groups are detailed in Fig. 7a. The elastic moduli of both anterior and posterior mitral valve chordae were up to an order of magnitude higher than these reinforced models; however, statistical analysis did not indicate a significant difference between printed models and biological chordae.

Ultimate strain, maximum force, and maximum stress data is displayed in Table 3 . The ultimate strain behavior of printed chordae was far higher than that of
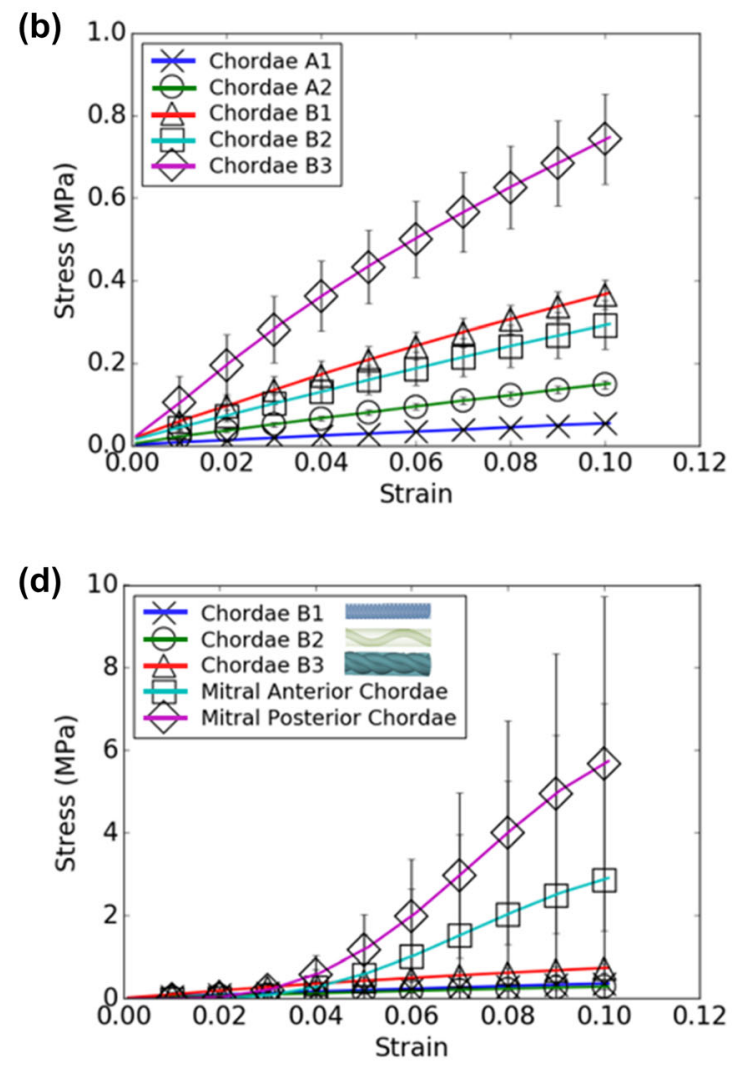

FIGURE 6. a, c Force-strain and b, d stress-strain curves for 3D printed mitral valve chordae samples for physiological strains. Results are presented as mean \pm SD. Model designs for composite printed structures are indicated on the figure legend. 

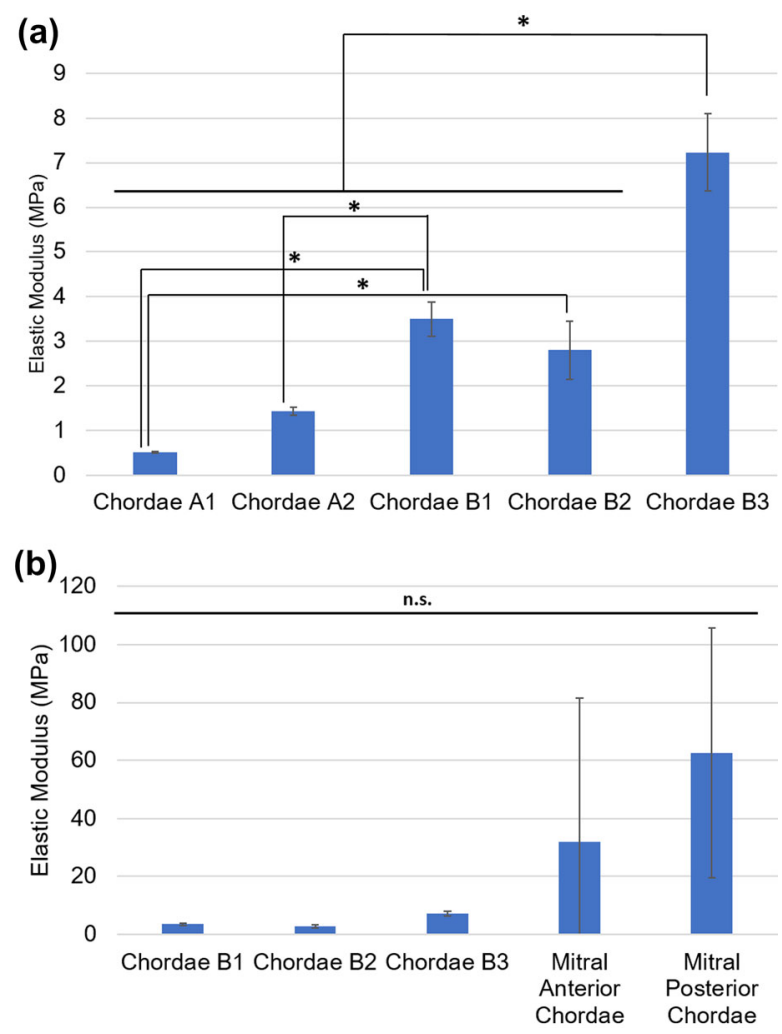

FIGURE 7. Elastic moduli for 3D printed mitral valve chordae samples. Moduli comparisons between (a) printed samples, and between (b) printed composite samples and biological samples. Moduli were measured between 0 and $10 \%$ strain. Results are presented as mean \pm SD. $N=3$ and ${ }^{*} p<0.05$ for all indicated group.

biological chordae. The homogeneous chordae models A1 and A2 did not undergo failure prior to the maximum extension limit of the tensile testing instrument, indicating that their ultimate strains were higher than the maximum observed strain listed in Table 3. Generally, the printed materials displayed higher maximum forces and lower maximum stresses as compared to biological chordae. This observation is consistent with measurements of cross-sectional area of the printed and native chordae, where the cross-sectional area for printed reinforced chordae (Chordae B1, B2, and B3) was $5.11 \pm 0.28 \mathrm{~mm}^{2}$, and that of the native chordae was $0.50 \pm 0.47 \mathrm{~mm}^{2}$ (anterior) and $0.29 \pm 0.15 \mathrm{~mm}^{2}$ (posterior).

\section{Mechanical Testing of 3D Printed Material at Different Strain Rates}

Samples printed using Agilus material were found to produce higher stresses at the same strains if tested at a higher strain rate (Fig. 8). Trends for increases in stress response with increase in testing rate were also preserved for sample force-strain curves (data not shown). The degree of increase in material stiffness with increasing strain rate seemed independent of printed material architecture, i.e., trends for increases in stress response with increase in testing rate were preserved between leaflets with a layered core-and-shell structure and chordae with embedded reinforcements of higher stiffness.

\section{DISCUSSION}

3D printing is becoming increasingly popular for the fabrication of patient-specific cardiovascular models for planning complex surgical procedures. However, most of these models are printed using materials with insufficiently characterized mechanical properties, resulting in a poor understanding of the similarity between printed patient-specific models and actual patient biological tissue. This study worked towards designing 3D printed constructs fabricated with the photopolymers Agilus and Rigur in a combination of different stiffnesses that best approximated the mechanical properties of tissue from components of the mitral valve apparatus. Inspiration from biological architecture was used to fabricate 3D printed mimics of mitral valve annuli, leaflets, and chordae. Uniaxial tensile testing was performed on the resulting constructs and the measured mechanical properties were compared to those of the target biological tissue.

The 3D-printed materials favorably replicated the material behavior of the mitral valve annulus at physiological strains. In vivo studies of ovine mitral valve annuli indicated a maximum physiological strain of $3-5 \%$ for the fibrous portion of the mitral annulus, and $6-10 \%$ for the muscular portion of the mitral annulus. ${ }^{20}$ Gunning and colleagues determined that the mitral annulus does not possess a homogeneous stiffness, and that the anterior portion of the annulus is much stiffer than the posterior portion. The mitral commissural and posterior annuli were found to have a median tangent modulus of between 1 and $3 \mathrm{MPa}$ at $2 \%$ strain, and $1-2 \mathrm{MPa}$ at $6 \%$ strain. The mitral anterior annuli, however, displayed a median tangent modulus of $28.15 \mathrm{MPa}$ at $2 \%$ strain and $21.55 \mathrm{MPa}$ at $6 \%$ strain. $^{7}$ Comparisons with the stress-strain curves and tangent moduli reported in this study indicate that that the sample group 'Annulus A3' represents the optimal choice for printing the anterior portion of the annulus, while the sample groups 'Annulus A1' and 'Annulus B1' would be suitable for replication of the posterior and commissural annulus segments. It should be noted that Rigur samples demonstrated lower stiffnesses than Agilus samples at higher shore values, although the shape of the stress-strain and force-strain curves for each group were similar. This indicates that 
(a)

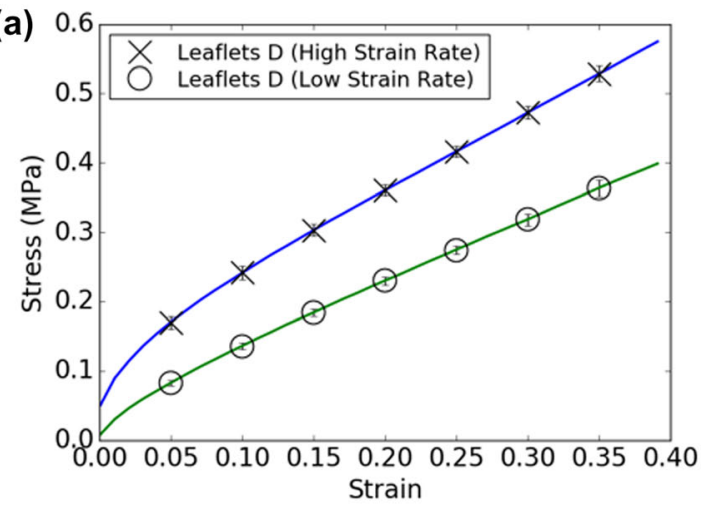

(b)

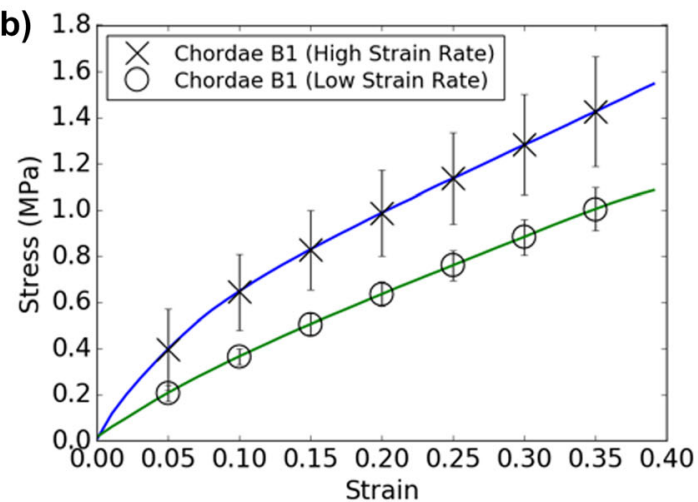

FIGURE 8. Stress-strain curves for 3D printed a patient-specific leaflets (Leaflets D) and b spiral-reinforced chordae (Chordae B1) at two different strain rates, $0.07 / \mathrm{s}$ (high strain rate) and $0.007 / \mathrm{s}$ (low strain rate). Results are presented as mean $\pm \mathrm{SD}$. $\boldsymbol{N}=3$ for all samples.

Agilus constructs should be used for mitral annulus sections requiring higher stiffnesses, and Rigur may be considered for mitral annulus sections requiring lower stiffnesses.

Direct comparisons with the study performed by Gunning and colleagues present a challenge as the study by Gunning utilized measurements of true stress and strain as opposed to measurements of engineering stress and strain; however, such comparisons may still work to inform broad design guidelines. The measured decrease in tangent modulus at $6 \%$ strain, compared to tangent modulus values at $2 \%$ strain for printed annuli reflects the nature of the stress-strain curve of the Agilus and Rigur photopolymers, which exhibit higher stiffness at low strain values followed by a region of lower stiffness. All printed materials examined in this study exhibited this form of mechanical nonlinearity.

3D printed mitral valve leaflet models were able to reproduce the magnitude of stresses and forces of native mitral leaflet tissue at physiological strains as well. Comprehensive understanding of the mechanical properties of mitral leaflets is crucial for the development of physiological patient-specific 3D printed models, as well as for the optimization and a design of novel catheter-based devices for mitral valve repair and replacement. This understanding could better inform clinical decision-making for determining medical device suitability and sizing in order to maximize beneficial patient outcomes. A series of studies have investigated and sought to characterize the mechanical parameters of mitral valve leaflets. ${ }^{6}$ These studies have all indicated that mitral valve leaflets demonstrate mechanical nonlinearity and anisotropy, with a stressstrain curve that begins with a low-slope 'toe region', then transitions gradually to another linear region with a higher slope. These studies have also indicated that mitral valve leaflets are inhomogeneous, changing their mechanical properties going from anterior leaflet belly to the edge. ${ }^{21}$ However, specific measurements of certain mechanical properties such as maximum physiological radial strain values experienced by mitral valves have often varied between measurement technique and tissue source, ranging between approximately $15-25 \%$ strain. ${ }^{8,19}$

The maximum observed strain levels found in 3D printed samples of leaflets compared favorably with the ultimate strain values found in the porcine anterior and posterior leaflet samples measured in our study and well exceeded the maximum physiological strain values reported in these previous external studies. The architecture of sample groups 'Leaflets C' and 'Leaflets D' mimicked that of native leaflets, and the 'Leaflets D' group most closely matched the ultimate strain of the native leaflets. We also observed that the elastic moduli and ultimate stress measurements of printed leaflets were lower than those of porcine leaflets; however, this discrepancy was most exacerbated at higher, nonphysiological strains. Ultimate force measurements of printed leaflets indicate that if a physiological force response is required at larger strains, samples with geometries larger than those of native tissue will serve the same functional purpose. Ultimately, especially at strains characteristic of maximum physiological strains, printed leaflets were able to demonstrate approximately similar stress and force response to biological leaflet tissue despite the dissimilarity in the shape of the stress-strain curve between printed materials and biological leaflets.

Printed chordae were able to best match the stressstrain response of biological chordae at low strains, corresponding to the toe region of biological chordae. There are a series of studies on the mechanical properties of porcine and human chordae, but limited information on the ranges of strains experienced by mitral valve chordae under physiological pressures. Ritchie and colleagues performed experiments with 
porcine chordae under physiological pressure values and found a maximum strain of $4.29 \pm 3.43 \%$ throughout the cardiac cycle. ${ }^{18} \mathrm{Lim}$ and Boughner performed investigation of the mechanical properties of human chordae and reported that the human chordae underwent a maximum strain level of $13 \%$, where the toe region extended up to $6 \%$ strain and the linear region was from 6 to $12 \% .{ }^{13}$ Liao and colleagues found that chordae with different thicknesses have different stiffnesses and extensibilities. This study indicated a maximum measured strain level of $4.3 \%$ for thin chordae, and up to $20 \%$ for thicker chordae. ${ }^{12}$ The ultimate strain of chordae has been reported to be $22 \pm 1.2 \%$ by Zuo and colleagues. ${ }^{25}$ However, as physiological strain levels are largely confined to within $10 \%$ strain, we investigated the elastic modulus and forces within this physiological range.

In this study, we attempted to approximate the mechanical behavior of human chordae by replicating their elastic moduli, stress-strain curves, and forcestrain curves. However, the introduction of embedded reinforcements of higher stiffness did not result in nonlinearity like that seen in biological tissue; in fact, the constructs retained the nonlinearity of opposite concavity seen in the printed annulus and leaflet samples. Future studies should involve an analysis of the flexural properties of similar printed constructs to determine if the use of reinforcements allows the constructs to exhibit greater flexibility than homogeneous constructs while maintaining mechanical stiffness.

Printed chordae constructs did demonstrate approximately similar mechanical behavior to biological chordae. Statistical analysis did not indicate a significant differences in elastic modulus between the printed and biological chordae; however, this was likely a result of the large variation in mechanical behavior between replicates for the biological samples. Testing a range of chordae from various locations of various thicknesses as a single group, in addition to the base variability of biological samples, may have contributed to this outcome. The force response of the printed constructs exceeded that of the biological chordae at all strains, and their stress response fell short at higher strains. This outcome indicates that the use of patient-specific geometries with these chordae constructs will almost certainly result in a force response that would fall short of being physiologically relevant at higher strains. Therefore, to match biological forces most closely for accurate modelling of TMVR therapies, it may be best to deviate from patient-specific chordae geometries and instead use

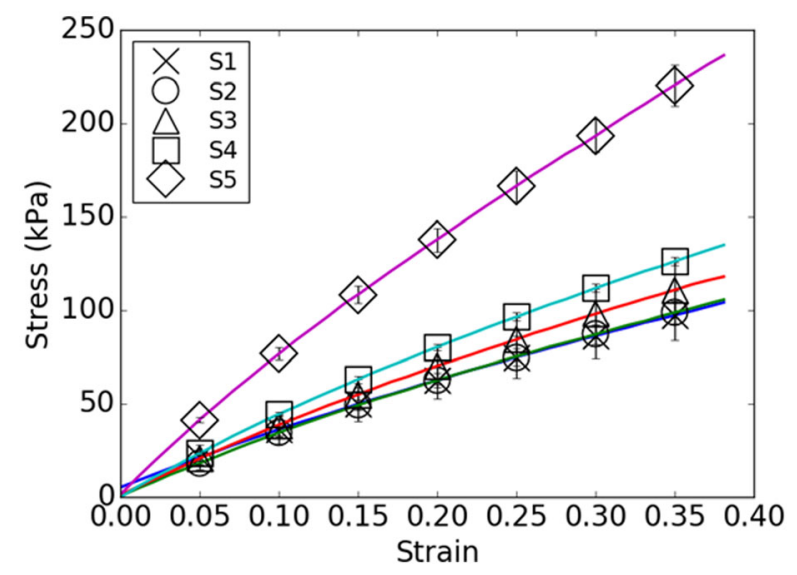

FIGURE 10. Stress-strain curves for printed chordae corresponding to $3 \mathrm{D}$ models. Results are presented as mean \pm SD. $N=3$ for all samples.

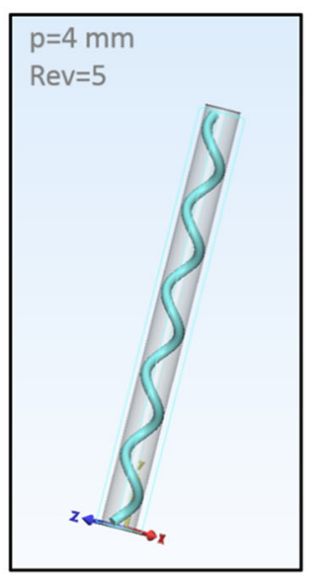

S1

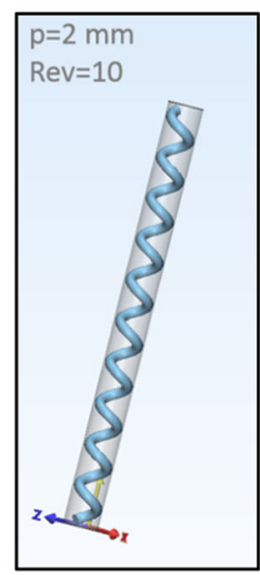

S2

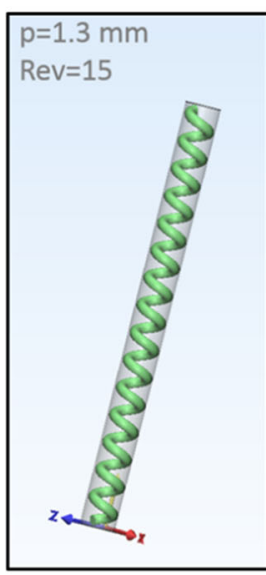

S3

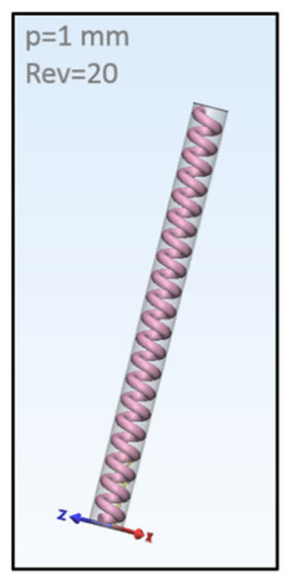

S4

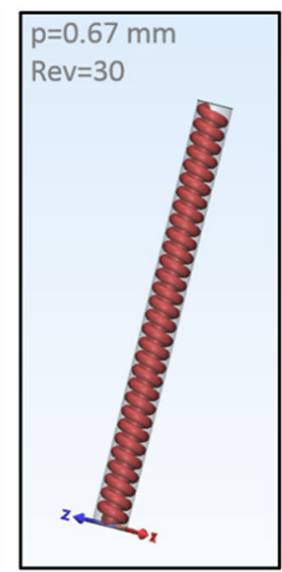

S5

FIGURE 9. Digital 3D models of spiral-reinforced chordae with different pitches. A range of Agilus 3D-print materials were used for manufacturing chordal elements. Agilus Shore $\mathbf{2 7}$ was used for the base material (cylinder), and Agilus Shore $\mathbf{7 0}$ was used for the spiral reinforcements. Spiral diameter was set to be $1.7 \mathrm{~mm}$, and reinforcement diameter was set to be $0.5 \mathrm{~m}$. 
slightly larger printed chordae constructs to compensate for their comparatively low stiffness. In our preliminary studies, we were able to accurately model the TMVR implantation in the mitral valve apparatus with slightly thicker chordae.

Constructs made of Agilus material may act mechanically different if experiencing static loading vs. rapid dynamic loading. Further work performed with this class of material should thus take this rate-dependent mechanical response into account, as physiological loading rates must be properly measured and employed if an understanding of material response under physiological conditions is desired. Physiological loading rates on components of the mitral valve apparatus tend to be much higher than those used in this study. The porcine anterior mitral valve leaflet was determined to experience maximum strain rates of approximately $10 / \mathrm{s}(1000 \% / \mathrm{s}),{ }^{19}$ while porcine mitral valve chordae of various sizes and from various locations experienced loading strain rates of approximately $0.7 / \mathrm{s}(70 \% / \mathrm{s}$, with error bar ranges between 20 and $130 \% / \mathrm{s}) .{ }^{18}$ These values stand in contrast to the strain rate used in this study for printed materials, which was around $0.007 / \mathrm{s}(0.7 \% / \mathrm{s})$. It is thus possible that Agilus constructs may demonstrate higher stiffnesses that those reported in this study when deployed under such conditions.

\section{CONCLUSIONS}

The use of 3D printed materials capable of replicating patient-specific geometries while also demonstrating biologically relevant mechanical properties could significantly improve the design and testing pipeline for medical devices, particularly the medical devices that are deployed in vivo. In this study, we demonstrate that:

(i) The photopolymers Agilus and Rigur can approximate the mechanical properties of components of the mitral valve at physiological strain levels.

(ii) That composite structures made of combinations of these photopolymers printed at different stiffnesses can recapitulate broad structural characteristics of these components, resulting in $3 \mathrm{D}$ printed mimics of mitral valve annuli, leaflets, and chordae.

(iii) That composites made of Agilus and Rigur are worth further investigation for the development of robust testing platforms to study the interactions between TMVR devices and biological tissue.
CONFLICT OF INTEREST Dr. Stephen H. Little holds a volunteer position as the President Elect of the American Society of Echocardiography.

\section{APPENDIX}

Illustration of iterative design process for printed chordae

In order to generate the finalized designs for 3Dprinted constructs, a series of iterative experiments were performed for all mitral valve subcomponents discussed in this study. Here, we illustrate this process for 3D-printed chordae structures with spiral reinforcements. In the experiment described henceforth, the thickness of the reinforcement was kept constant and the pitch was modified to between 5 and $30 \mathrm{rev-}$ olutions within a $20 \mathrm{~mm}$ sample length (Fig. 9).

From the stress-strain curves, it is evident that the spiral configuration with the highest pitch demonstrated the highest stiffness. Given the high stiffness of native chordae, this design was then selected for comparison against chordae with sinusoidal and ropelike reinforcements (Fig. 10).

\section{OPEN ACCESS}

This article is licensed under a Creative Commons Attribution 4.0 International License, which permits use, sharing, adaptation, distribution and reproduction in any medium or format, as long as you give appropriate credit to the original author(s) and the source, provide a link to the Creative Commons licence, and indicate if changes were made. The images or other third party material in this article are included in the article's Creative Commons licence, unless indicated otherwise in a credit line to the material. If material is not included in the article's Creative Commons licence and your intended use is not permitted by statutory regulation or exceeds the permitted use, you will need to obtain permission directly from the copyright holder. To view a copy of this licence, visit http://crea tivecommons.org/licenses/by/4.0/.

\section{REFERENCES}

\footnotetext{
${ }^{1}$ Angelini, A., S. Y. Ho, R. H. Anderson, M. J. Davies, and A. E. Becker. A histological study of the atrioventricular junction in hearts with normal and prolapsed leaflets of the mitral valve. Heart. 59:712-716, 1988.
} 
${ }^{2}$ Biglino, G., P. Verschueren, R. Zegels, A. M. Taylor, and S. Schievano. Rapid prototyping compliant arterial phantoms for in-vitro studies and device testing. J. Cardiovasc. Magn. Reson. 15:2, 2013.

${ }^{3}$ Cloonan, A. J., D. Shahmirzadi, R. X. Li, B. J. Doyle, E. E. Konofagou, and T. M. McGloughlin. 3D-printed tissuemimicking phantoms for medical imaging and computational validation applications. 3D Print. Addit. Manuf. 1:14-23, 2014.

${ }^{4}$ El-Tallawi, K. C., P. Zhang, R. Azencott, J. He, E. L. Herrera, J. Xu, et al. Valve strain quantitation in normal mitral valves and mitral prolapse with variable degrees of regurgitation. JACC Cardiovasc. Imaging. 14(6):1099$1109,2021$.

${ }^{5}$ Grande-Allen, K. J., J. E. Barber, K. M. Klatka, P. L. Houghtaling, I. Vesely, C. S. Moravec, et al. Mitral valve stiffening in end-stage heart failure: evidence of an organic contribution to functional mitral regurgitation. J. Thorac. Cardiovasc. Surg. 130:783-790, 2005.

${ }^{6}$ Grande-Allen, K. J., and J. Liao. The Heterogeneous Biomechanics and Mechanobiology of the Mitral Valve: Implications for Tissue Engineering. Curr. Cardiol. Rep. 13:113-120, 2011.

${ }^{7}$ Gunning, G. M., and B. P. Murphy. Determination of the tensile mechanical properties of the segmented mitral valve annulus. J. Biomech. 47:334-340, 2014.

${ }^{8}$ He, Z., J. Ritchie, J. S. Grashow, M. S. Sacks, and A. P. Yoganathan. In vitro dynamic strain behavior of the mitral valve posterior leaflet. J. Biomech. Eng. 127:504-511, 2005.

${ }^{9}$ Kheradvar, A., E. M. Groves, C. A. Simmons, B. Griffith, S. H. Alavi, R. Tranquillo, et al. Emerging trends in heart valve engineering: Part III. Novel technologies for mitral valve repair and replacement. Ann. Biomed. Eng. 43:858870, 2015.

${ }^{10}$ Kligfield, P., D. Levy, R. B. Devereux, and D. D. Savage. Arrhythmias and sudden death in mitral valve prolapse. Am. Heart J. 113:1298-1307, 1987.

${ }^{11}$ Kunzelman, K. S., R. P. Cochran, S. S. Murphree, W. S. Ring, E. D. Verrier, and R. C. Eberhart. Differential collagen distribution in the mitral valve and its influence on biomechanical behaviour. J. Heart Valve Dis. 2:236-244, 1993.

${ }^{12}$ Liao, J., and I. Vesely. A structural basis for the size-related mechanical properties of mitral valve chordae tendineae. $J$. Biomech. 36:1125-1133, 2003.

${ }^{13}$ Lim, K. O., and D. R. Boughner. Mechanical properties of human mitral valve chordae tendineae: variation with size and strain rate. Can. J. Physiol. Pharmacol. 53:330-339, 1975.

${ }^{14}$ Maragiannis, D., M. S. Jackson, S. R. Igo, R. C. Schutt, P. Connell, J. Grande-Allen, et al. Replicating patient-specific severe aortic valve stenosis with functional $3 \mathrm{D}$ modeling. Circ. Cardiovasc. Imaging. 8:e003626, 2015.

${ }^{15}$ Millington-Sanders, C., A. Meir, L. Lawrence, and C. Stolinski. Structure of chordae tendineae in the left ventricle of the human heart. J. Anat. 192:573-581, 1998.

${ }^{16}$ Nkomo, V. T., J. M. Gardin, T. N. Skelton, J. S. Gottdiener, C. G. Scott, and M. Enriquez-Sarano. Burden of valvular heart diseases: a population-based study. Lancet. 368:1005-1011, 2006.

${ }^{17}$ Puperi D. Biomimetic heterogeneous scaffolds for a layered tissue engineered heart valve [Internet]. 2016 [cited 2020 Dec 21];Available from: https://scholarship.rice.edu/handl e/1911/96554.

${ }^{18}$ Ritchie, J., J. Jimenez, Z. He, M. S. Sacks, and A. P. Yoganathan. The material properties of the native porcine mitral valve chordae tendineae: an in vitro investigation. $J$. Biomech. 39:1129-1135, 2006.

${ }^{19}$ Sacks, M. S., Z. He, L. Baijens, S. Wanant, P. Shah, H. Sugimoto, et al. Surface Strains in the anterior leaflet of the functioning mitral valve. Ann. Biomed. Eng. 30:1281-1290, 2002.

${ }^{20}$ Timek, T. A., G. R. Green, F. A. Tibayan, D. T. Lai, F. Rodriguez, D. Liang, et al. Aorto-mitral annular dynamics. Ann. Thorac. Surg. 76:1944-1950, 2003.

${ }^{21}$ Vekilov, D. P., M. Singh, S. R. Aglyamov, K. V. Larin, and K. J. Grande-Allen. Mapping the spatial variation of mitral valve elastic properties using air-pulse optical coherence elastography. J. Biomech. 93:52-59, 2019.

${ }^{22}$ Vukicevic, M., D. S. Puperi, K. Jane Grande-Allen, and S. H. Little. 3D Printed modeling of the mitral valve for catheter-based structural interventions. Ann. Biomed. Eng. 45:508-519, 2017.

${ }^{23}$ Wan, B., M. Rahnavardi, D. H. Tian, K. Phan, S. Munkholm-Larsen, P. G. Bannon, et al. A meta-analysis of MitraClip system versus surgery for treatment of severe mitral regurgitation. Ann. Cardiothorac. Surg. 2:683-692, 2013.

${ }^{24}$ Wang, K., Y. Zhao, Y.-H. Chang, Z. Qian, C. Zhang, B. Wang, et al. Controlling the mechanical behavior of dualmaterial 3D printed meta-materials for patient-specific tissue-mimicking phantoms. Mater. Des. 90:704-712, 2016.

${ }^{25}$ Zuo, K., T. Pham, K. Li, C. Martin, Z. He, and W. Sun. Characterization of biomechanical properties of aged human and ovine mitral valve chordae tendineae. J. Mech. Behav. Biomed. Mater. 62:607-618, 2016.

Publisher's Note Springer Nature remains neutral with regard to jurisdictional claims in published maps and institutional affiliations. 